\title{
University Research Policy - Structure or Results?
}

\author{
Bertrand L. Hansen *
}

Quest for Optimum, the Report of a Commission to Study the Rationalization of University Research, by L.-P. Bonneau and J.A. Corry, Volume I, 1972, Association of Universities and Colleges of Canada.

The predominant theme underlying this report is that university research can and ought to be split into two components - "frontier" research seeking new knowledge, and "reflective inquiry" which is reflection on the knowledge we already possess. The authors believe that this separation can be more than conceptual, that it can be in fact operational, and that the optimum research policy will be found in separate funding of the two types of university research which would require procedures and organizations in universities, provinces, regions, and at the federal level. Frontier research would be funded federally; reflective inquiry would be funded provincially.

It is the view of the authors of the report that in the overall rationalization of research in Canada there needs to be a sorting out of the role of university research which will be compatible with the universities' larger service of providing higher education to society.

The justification for what appears to be a very radical proposal is that up to this time few Canadian universities have taken a serious look at the objectives of research in the university. It is claimed that heavily research-oriented graduate work is overextended, standards for Ph.D. work are too loose, and there is considerable duplication. Federal research grants to universities do not cover overhead. Canada is far down the list in its total expenditure on $\mathrm{R}$ and $\mathrm{D}$, but of these expenditures basic research -

\section{Toronto.}

Bertrand L. Hansen, Associate Professor of Higher Education, University of 
insufficient in itself in total - is disproportionately high in relation to mission-oriented research.

In contrast to laissez-faire adherents who would let the weak in frontier research (and unfortunately some not so weak) fall by the wayside in the competition for support, the authors seek order in the allocation of resources to research and additionally protection of those whose bent is reflective inquiry rather than frontier research. They ask for a revision of policies on promotion and salary increases to ensure that the same weight is given to undergraduate teaching as to graduate teaching and research : if good teaching is not buttressed by funds for reflective inquiry, "the proponents of heavy concentration of research efforts and funds will have to face honestly the dilemma of deliberately debasing a number of Canadian universities into second-rate institutions by taking their support for research away from them."

Biases are revealed here. The optimum sought appears to be the best arrangement to protect certain elements of Canadian universities - the young universities, undergraduate teaching, the humanities, and to nurture the emerging social sciences in Canada. By recognizing the distinction between the two types of research, there would be, as the authors argue, more attention to undergraduate teaching, a suitable role for smaller universities without Ph.D. programmes, restoration of the humanities to a central place in the university, better frontier research with fewer researchers in proportion to the total number of university staff, development of centres of excellence and specialization in research in certain selected institutions, and clarification of federal and provincial responsibilities for support of university research.

The final chapters of the report propose models for rationalizing research at the three functional levels: university, provincial and federal. The models are intended to ensure that goals of university research would be examined; that preferred mixes of basic and applied research would be determined ; that screening mechanisms for rejecting and accepting projects would be developed within the universities; that committee organizations would be formed at provincial and federal levels for setting research objectives, establishing priorities, maintaining inventories of programs, etc.

The report is readable and useful for clarifying issues, though overlong. What was said could have been said in many less pages; the authors' concerns for reflective inquiry are revealed in their penchant for discourse in the text. Reflective inquirers as well as frontier researchers reading it will be troubled, as I was, by the complete lack of data or empirical evidence in the report (not a single table, although general reference is given to the substantial background researches for the Macdonald, OECD, and the Senate Special Committee on Science Policy reports) and the ease with which university research is split into two components and then made operational. It is possible to separate research in many ways e.g. basic/applied, sponsored/unsponsored, synthetic/analytic. One may conceptualize theoretically this particular dichotomy of the two types of research; it is 
quite a different thing to suggest that it become operational without empirical evidence to demonstrate the likely utility. To suggest that the frontier researcher does little reflective inquiry is quite wrong; the processes of deduction, induction, analysis, and synthesis are characteristics of all good research - iterative and inseparable in operation. For much university research this particular separation would be artificial. The authors' emphasis on the difference is helpful, however, in stressing the importance of synthesis and the inductive process, reflective inquiry if you will, to the broad range of university research. Not all university teachers need to be involved in experimental research for their entire university careers. Depending on the circumstances, they may be engaged in the reflective inquiry mode for substantial periods of time, years perhaps. It is less certain, however, that as a condition of employment as a university teacher, they should not have demonstrated a capacity for scholarly work.

What kinds of steering effects will be introduced by the proposals ? Civil-service type organizations and bureaucratic controls tend to optimize in an egalitarian way only; levels of excellence and bureaucracy in general tend to be inversely related. What kind of optimization do we desire ? How should we accommodate to the demands of the notso-strong, the emerging disciplines, and other aspirants? To what degree should we substitute structure, organization and control for results? Would separate funding with concomitant controls be preferable to reduced overall funding with little or no controls? The authors' preference is for the former. For my part, I am generally pessimistic about the prospects of holding people who strive for excellence by forcing them continually to respond to a rigidly bureaucratic structure. While it may not be intended to have this effect, the breaking-up of university research funding will inevitably introduce forces which tend toward the build-up of organizational control structures. Direct work on research will be replaced by indirect work on procedures and controls at all levels. We should proceed with very great caution in giving over to governments decisions about what kinds of university research (as distinct from sponsored research) will be productive. The time frame for measuring productivity in the politician's mind necessarily must be very short. If a university is to remain a university, the time frame cannot be short. Commitment to scholarship and research protects the university from the dangers of having to flit from one social policy to another over relatively short periods of time. What would be our condition now if some universities had not maintained Chinese studies when they were not politically popular? Who is to say that the presently large unit costs of Islamic studies will not have a very large payoff in the future ? These are matters which are most properly in the domain of the universities. They must retain control over internal distribution of funds with a minimum of steering pressure from external formulae.

The points raised by the report should be a reminder to the universities to think very carefully about the components of university research, how they interrelate, what proportions of each there should be. It is possible for external formulae to be devised 
for distributing operating funds which would recognize the components of research in terms of total amounts, provided they could be tied to correlative growth indicators. But the universities' responsibility to distribute such funds internally should be preserved intact. It is important that we avoid substituting costly structure for results. Universities should be concerned lest the worthy.goals sought for research rationalization remain unrealized at the same time that essential decision-making powers of the university are abdicated to external bodies. 